\title{
A verdade na biomedicina, reações adversas e efeitos colaterais: uma reflexão introdutória
}

CHARLES DALCANALE TESSER •

RESUMO

Apresenta-se uma reflexão sobre a construção e uso das verdades biomédicas, contextualizada no ambiente da atividade clínica, e suas relações com a missão ética dos médicos. Analisam-se aspectos problemáticos de transformações realizadas pela biomedicina em dois momentos críticos da produção de verdades: 1) a efetivação da cura e 2) sua relação com os tratamentos. A missão ética da biomedicina é curar e tratar dos doentes e promover a saúde, mas seu saber é voltado e construído para a cura ou controle de doenças específicas. As verdades produzidas cientificamente alimentam a tendência à conversão do doente em doença e da cura em eliminação ou controle de doenças e riscos. Isso está envolvido num processo de "desresponsabilização" ética e epistemológica dos curadores biomédicos. A "desresponsabilização" ética transforma a identidade dos médicos, que passam a se ver mais como cientistas e menos como curadores de pessoas. A "desresponsabilização" epistemológica é a projeção de toda competência para produção de saber verdadeiro na ciência biomédica. Ela isenta o profissional médico de produzir saber para sua própria atividade, desqualifica o saber produzido na prática (ou arte) médica, desqualifica todo saber do doente e de outros curadores nãocientíficos. Defende-se uma perspectiva crítica, flexível e pragmática na relação com as verdades científicas, e uma submissão dessa relação à missão curadora dos profissionais, centrada nas pessoas e na busca da cura vivida, entendida como aumento da autonomia e do grau de liberdade vivida. Ressaltase a necessidade da reconstrução da responsabilidade ético-epistemológica dos médicos.

Palavras-chave: Medicina - prática; Filosofia; metodologia; saúde pública; ética médica.

Recebido em: 30/01/2007.

Aprovado em: 26/03/2007. 


\section{Introdução}

Os profissionais de saúde, principalmente os médicos, estão envolvidos no seu dia-a-dia com questões epistemológicas relativas à verdade. "Epistemológicas" é um termo amplo que diz respeito a um campo simultaneamente científico e filosófico, referente tanto à teoria do conhecimento quanto à filosofia da ciência (GAYON, 2006).

Em particular, é relevante compreender como se constroem os conhecimentos, como são validados e legitimados os mesmos na ciência biomédica, além de como os mesmos são usados. Se essa validação ocorre, influencia toda a sociedade, já que a ciência logrou ocupar no Ocidente o lugar de maior produtora de "conhecimentos corretos" ou "verdades" após a modernidade.

Essas verdades, via de regra, não são vistas como um consenso provisório e momentâneo sócio-histórico-culturalmente localizado - como defende, por exemplo, Rorty (2002) - mas sim como descrevendo a realidade tal qual ela é. Que essas verdades sejam dirigidas e coagidas por paradigmas (KUHN, 1986 e 1989) ou estilos de pensamento (FLECK, 1986), conectadas com certos valores sociais e políticos como o controle (LACEY, 1998), vinculadas com redes sociais, técnicas e políticas (LATOUR, 1997, 2000 e 2001), tudo isso não impede que tais verdades continuem sendo consideradas na biomedicina, na área da saúde e fora dela, como um saber que se aproxima assintoticamente da "Verdade", vista como descrição fiel da realidade.

Em todo caso, os conhecimentos biomédicos são, na prática - e é isso que mais interessa ao clínico e ao doente - considerados verdades do ponto de vista operacional. O profissional confia que está fazendo o melhor, o verdadeiro, ao firmar interpretações (diagnósticos) e prescrever tratamentos com base nos saberes científicos. O doente, leigo nesses conhecimentos especializados, recebe a versão do médico com uma dose grande de confiança; via de regra, como verdade - supondo que tenham sido cumpridos a contento alguns rituais e quesitos éticos mínimos da relação de cura, culturalmente aceitos pelo paciente. Podese dizer que esse é o senso comum da ciência biomédica (analogamente a Bronowski [1977]). Assim, a verdade sobre o adoecimento, a cura e os tratamentos têm valor crucial para todos, profissionais de saúde e pacientes, embora com conotações e consequiência distintas para ambos os grupos.

A proposta deste texto é apresentar uma reflexão sobre alguns imbróglios epistemológicos e éticos envolvidos no uso cotidiano da idéia de verdade na 
biomedicina e contribuir para seu entendimento. Embora dedicada mais aos profissionais médicos, a discussão interessa também ao leigo e aos demais profissionais de saúde, que podem dele se beneficiar, refletindo algo sobre os meandros do saber e prática biomédicos.

Para isso, são desenvolvidas adiante algumas breves reflexões filosóficas, epistemológicas e éticas acerca da construção da verdade na biomedicina contemporânea, discutindo pontos considerados centrais da tecnificação científica do saber e da prática biomédicos, tais como sua centralidade nos conceitos operacionais das doenças e as metodologias de validação da terapêutica. A construção da verdade e seu uso biomédico são relacionados com a missão social de curadores dos profissionais médicos, cuja ética deve primar pela cura dos doentes, mas cujo saber é voltado para cura ou controle das doenças.

Refletir sobre a construção e o uso das verdades na medicina pode ajudar na compreensão e na superação de algumas questões práticas, políticas e terapêuticas relevantes, comumente tornadas insolúveis pelo uso automático do senso comum acima mencionado. A relevância diz respeito à relação dos médicos com os pacientes, à relação dos médicos com seu saber e com os demais saberes em saúde-doença não-científicos, tradicionais, alternativos ou complementares.

Embora esboce uma reflexão filosófica, o artigo não apresentará uma discussão sobre a verdade nos termos dessa disciplina. Um enfoque acadêmico, centrado na Filosofia, desviaria seu rumo. A idéia é agir como um detetive que busca pistas para entender como agimos (nós, cientistas e médicos) e certos problemas decorrentes dessa ação. Perscrutadas algumas destas pistas, ensaiase uma pequena análise sobre suas relações com a prática biomédica e algumas de suas conseqüências socioculturais, para chegar ao final em algumas proposições e sugestões quanto ao tema. A discussão é baseada em experiência clínica e estudo de mestrado e doutorado em Saúde Coletiva (TESSER, 1999 e 2004).

\section{Sobre a construção da verdade na biomedicina}

Uma primeira pista importante para se compreender a construção da idéia de verdade na biomedicina, que pode ser também um princípio ético e terapêutico geral na saúde, é que a cura está vinculada a uma pessoa doente. Tudo começa com o adoecer das pessoas e seus sofrimentos. Esse vínculo deve ser o princípio, o fim e o meio. Ele deve escrutinar os métodos, os saberes 
e as tecnologias, de um ponto de vista da prática. Aqui reside um ponto de imbricação entre ética e epistemologia, comumente pouco destacado ou trabalhado.

Uma segunda pista é que a cura diz sempre respeito a um aumento do bem-estar e do grau de liberdade vivida do indivíduo (ILLICH, 1981; NOGUEIRA, 2003), ou de um aumento do poder de instituir normas vitais (CANGUILHEM, 1978), ou ao resgate e incremento de sua autonomia (CAMPOS, 1992), ainda que considerada em termos de coeficiente de cura ou graus de cura, temporária ou parcial.

Uma terceira pista é a transformação da primeira pista pela biomedicina: a pessoa doente, traduzida no modo de pensar científico, metamorfoseia-se na doença. Há aí um sutil e importante processo, ao mesmo tempo epistemológico e de crucial importância ética: a tradução científica da pessoa doente a transforma em alguém portador de uma doença, para, em seguida, começar a desfocar da primeira (a pessoa) para focalizar na segunda (a doença), que cresce em importância e ameaça monopolizar a atenção, como objeto do trabalho médico (CAMARGO JUNIOR, 2003; ALMEIDA FILHO, 1992; GONÇALVES, 1994; TESSER, 1999; CLAVREUL, 1983).

Há ainda uma quarta pista: o tratamento, ou terapêutica, um mediador entre a pessoa e a maior liberdade. Em outros termos, uma ação intermediária fruto do saber/fazer do terapeuta com a participação do doente, que envolve uma troca assimétrica de interpretações, símbolos e explicações, as quais vão mais do profissional em direção ao doente.

Uma quinta pista é o procedimento adotado pela ciência na sua busca de objetividade e universalidade. É a padronização e objetivação das doenças e sintomas, com a aceitação de que sua eliminação ou controle está implicada na cura. O que era aumento de liberdade vivida, melhora relativa dos sintomas, limitações e sofrimentos, com mais ou menos transformações nas pessoas e seu modo de viver, passa a ser traduzido pela ciência biomédica como eliminação da entidade doença (patologia, síndrome etc.).

Houve uma troca nos termos finais dos fins da terapêutica, no que diz respeito ao saber científico: a maior liberdade vivida passa a se caracterizar cientificamente como ausência da doença (no modelo ideal e operacionalmente, supõe-se). Assim, o proceder do terapeuta tende a ser dominado pela padronização operacional e científica das doenças, que seria um instrumento indireto de eficaz intermediação entre o terapeuta e o doente no rumo da 
cura. Frente a uma pessoa doente, buscando aumentar sua liberdade (restrita pela doença), o terapeuta presta atenção em certos aspectos dessa pessoa para caracterizar a doença (o mal, a causa da restrição da liberdade) e dedicase, então, a combatê-la, sendo sua eliminação ou controle a cura ou o tratamento, respectivamente.

Dessa forma, transformaram-se quase convencionalmente, por uma operação epistemológica, o adoecimento e a cura. A biociência construiu seus métodos de produção de saber sobre a doença e de testagem e validação dos meios de cura (terapêutica) sempre se pautando pela busca da verdade, tendo as definições e redefinições operacionais de doença como centro aglutinador de objetividade e universalidade a orientar o processo.

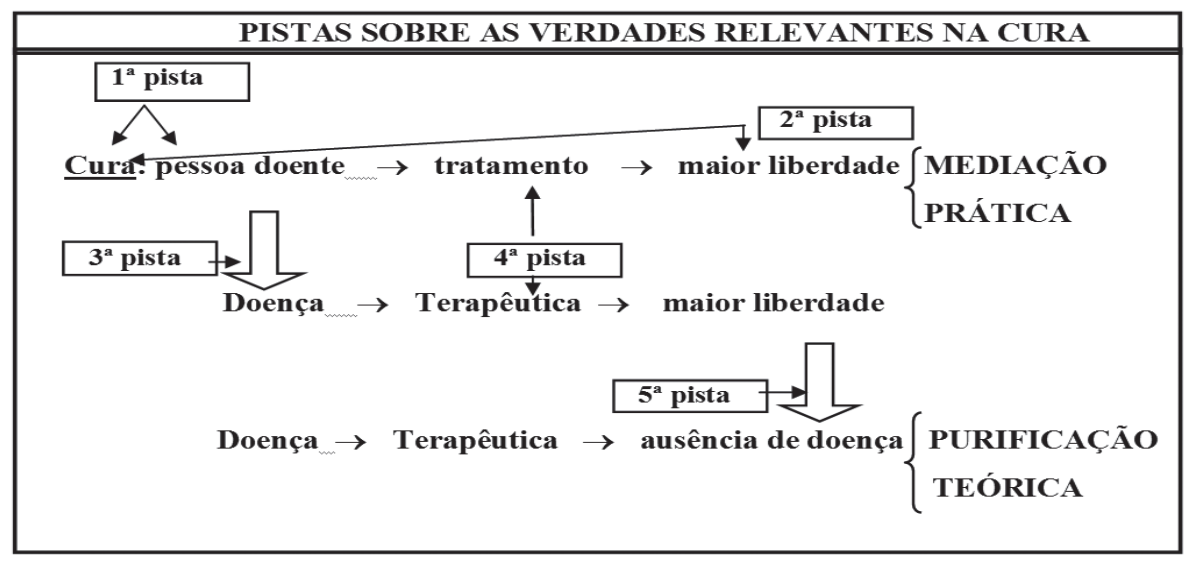

Note-se que, na primeira linha do esquema acima, o que está em jogo é a missão social do curador, qualquer que ele seja, inclusive o médico. Esta é a missão ética dos profissionais de saúde, encarregados de realizar uma mediação prática entre os doentes e maior grau ou coeficiente de liberdade, através dos tratamentos, orientações etc. Esse é o ambiente da prática clínica.

Ocorre que as verdades utilizadas e mesmo em parte produzidas (ao se fazer um diagnóstico, por exemplo) pelos médicos são regradas e produzidas progressivamente pelo ambiente científico, em que ocorre uma "purificação teórica" - no dizer de Latour (2001 e 2002) - ou científica. Típica da modernidade e da ciência, relativamente longe das necessidades e valores da prática curadora cotidiana, tal purificação é relativa às doenças, já que a 
saúde não logrou obter um estatuto cientificamente legítimo, operacionalizável e instituído (LUZ, 1996; CZERESNIA; FREITAS, 2003).

\section{Primeiras reflexões: reações adversas e efeitos colaterais da "purificação científica"}

Como vários autores já demonstraram, diminuíram drasticamente as discussões teóricas sobre as doenças na biomedicina na passagem do século XIX para o XX, quando à noção de localização da doença no corpo nascida da anátomo-patologia se associou a descoberta dos microorganismos por Pasteur, até se constituírem as duas no cerne das definições das doenças infecciosas e essa concepção ontológico-localista e mecânico-causal se expandir para todo o universo das doenças dos humanos, resultando na constituição da entidade "doença", a ser tratado especificamente (ALMEIDA, 2002; SAYD,1998).

No início (primeira pista), a verdade estava enraizada no adoecer humano, na limitação de liberdade, no sofrimento vivido pelo doente, na sua busca de ajuda e, finalmente, na relação de maior ou menor sucesso da terapêutica realizada na direção da cura (aumento da liberdade). Existem aí dois tipos de verdade cruciais que interessam mais do ponto de vista da missão social e ética do "curador" e dos pacientes, ou seja, do ponto de vista da prática: 1) verdade da efetivação da cura da pessoa (cura vivida, aumento da liberdade); e 2) verdade do vínculo da terapêutica com a cura ou prevenção (se a terapêutica realmente ajudou ou foi a responsável pela cura ou prevenção).

Note-se que passo ao largo, conscientemente, da avaliação das verdades dos diagnósticos, posto que estou assumindo a possibilidade de várias versões diagnósticas para o mesmo adoecimento, assumindo a possibilidade, conforme Luz (1996), Fleck (1986), Kuhn (1986 e 1989) e Feyerabend (1991 e 1985), de que mais de uma racionalidade médica ou terapêutica, mais de um estilo de pensamento, paradigma ou tradição especializada em saúdedoença, respectivamente, possam construir interpretações dos adoecimentos com sentidos coerentes e veracidade, e permitam intervenção "curadora" de diferentes formas com eficácia.

No fim do processo de cientifização da biomedicina - em curso -, há igualmente dois tipos de "verdades", agora científicas, correspondentes àquelas do início, porém transformadas. A verdade da cura da pessoa virou cura (ausência) da doença cientificamente definida, ou seu controle. A verdade sobre 
a terapêutica ter sido responsável pela cura manteve-se, só que restrita à cura da doença e, por outro lado, expandida e atrelada ao coletivo dos doentes dessa mesma doença. Isso é exigido pela legitimação metodológica científica (epidemiológica) e se expressa como associação estatística que se quer depuradora do efeito placebo e comparadora entre duas situações de evolução clínica dos critérios operacionais de definição da cura ou melhora da doença ou dos sintomas (remédio x placebo; remédio x remédio, remédio x nada), no que consistem os ensaios clínicos controlados.

\begin{tabular}{|c|c|}
\hline \multicolumn{2}{|c|}{ VERDADES - MOMENTOS CRÍTICOS } \\
\hline $\begin{array}{l}\text { Adoecimento vivido e tratamento } \\
\text { (Trabalho de mediação clínica) }\end{array}$ & $\begin{array}{l}\text { Doença e terapêutica na biociência } \\
\text { (Trabalho de purificação científica) }\end{array}$ \\
\hline $\begin{array}{ll} & \text { Efetivação da cura vivida } \\
& \text { Vinculação do tratamento à cura }\end{array}$ & $\begin{array}{l}\text { Efetivação da cura da doença } \\
\text { Associação entre terapêutica e cura da doença } \\
+ \text { depuração do efeito placebo }+ \text { comparação } \\
\text { com nada }+ \text { comparação com outra } \\
\text { terapêutica. }\end{array}$ \\
\hline
\end{tabular}

Essa dupla transformação, operada pela "cientificização" da biomedicina como medicina oficial, está envolvida num processo de esvaziamento da dignidade, da competência e da responsabilidade epistemológicas e éticas, na prática e implicitamente (não no discurso), dos profissionais de saúde e de seu labor cotidiano (TESSER, 2004). O que merece ênfase e análise é o afastamento da legitimação epistemológica do cotidiano da clínica.

A validação e estabelecimento das verdades vão migrando do dia-adia dos tratamentos e evoluções dos doentes reais, das casuísticas dos médicos, progressivamente para o âmbito dos estudos científicos de validação das intervenções, tipicamente os ensaios clínicos controlados e os estudos de coortes. Ainda que essa migração ocorra bem parcialmente e mais lentamente do que os racionalistas e cientificistas gostariam, o importante é que ela logrou legitimidade científica e pública na corporação destes curadores. Seu orgulho, em termos de sabedoria curadora, passa a ser saber os últimos resultados das metanálises e dos grandes estudos caso-controle sobre as diversas doenças, síndromes, medicamentos etc. Em outros termos, há uma progressiva desresponsabilização e alienação dos indivíduos curadores biomédicos, 
quanto à produção própria de conhecimentos para uso prático, seus resultados e conseqüências. Tal responsabilidade passa a ser remetida à pesquisa científica biomédica.

Uma mudança histórica nessa biomedicina nas últimas décadas pode ser considerada sintoma desse processo: um maior intervencionismo químico geral e um tratamento dos pacientes progressivamente standardizado em função das doenças e riscos, com menor preocupação com variabilidades singulares, reações individuais, idiossincrasias orgânicas, contextos psicossociais etc., como se a biomedicina cada vez mais considerasse os pacientes homogêneos entre si (DALMASO, 1998).

Essa alienação induz os profissionais a se remeterem sempre à instituição e a seus saberes, cujas tecnologias devem operar eficazmente, devido à cientificidade, objetividade e universalidade supostas do saber, segundo a concepção dominante, de viés marcadamente positivista. Tal exteriorização da competência epistemológica induz a uma desconfiança, a uma dependência e a uma desresponsabilização do curador biomédico e, a posteriori, dos doentes. Ambos passam a necessitar progressivamente de validação científica para suas vivências, práticas e saberes. Ambos começam a desconfiar do que sentem, vivem, conjecturam, percebem. O médico, especificamente, por ter sido educado numa tradição que pensa monopolizar a verdade essencial sobre os adoecimentos e curas (CLAVREUL, 1983), vê-se em "maus lençóis". Começa a acreditar nos doentes, enquanto sua nosologia consegue interpretar o quadro de adoecimento "cru" (como trazido pelo doente) e nele intervir, e aí tende a encerrar-se sua responsabilidade. Nesse momento aparece explicitamente a indução da alienação ética mencionada.

Isso se relaciona centralmente com o fato de que a definição operacional de doença é a âncora, o eixo, a categoria ao redor da qual se organizou a "cientificização" da clínica e da pesquisa biomédica como a conhecemos hoje. Tal organização supõe que se esteja atacando a essência do problema, do adoecimento, na tradição teórica da ciência clássica.

Apesar de suspeitas, indícios e certo mal-estar gerais, não há uma percepção coletiva instituída de que os modelos e concepções biomecânicos que orientam a pesquisa biomédica possam estar sendo fonte de distanciamento entre o resultado esperado (a cura da pessoa) e a cura da doença cientificamente definida, ou mesmo entre os objetivos já restritos (cura ou controle das doenças) e os resultados terapêuticos: pouca coisa se cura para além das infecções, 
único tipo de doenças em que se fala cientificamente de cura sem mal-estar. Por outro lado, vive-se uma obsessão frustrada de controle de doenças crônicas crescentes em incidência, prevalência e gravidade.

A verdade, assim, passando a operar no universo das categorias científicas, continua a existir, mas metamorfoseada em termos de objetividade do quadro mórbido reduzido (sintomas, sinais e exames complementares que possibilitam o enquadramento diagnóstico) que permite a cura ou controle desse quadro. O paciente pode melhorar ou piorar com certo grau de independência dos critérios biomédicos, ou pode "trocar de doença", mas a verdade científica opera dentro dos parâmetros instituídos e assim está sempre preservada.

O primeiro tipo de verdades cruciais do mundo cotidiano, a verdade da efetivação da cura vivida, vai sendo progressivamente dominado e regrado na mente dos profissionais e, mais lentamente, também na dos doentes - via processo de medicalização social (cf. ILLICH, 1981; TESSER, 2006a,b) pelo saber biomédico, centrado nas doenças e síndromes estabelecidas. Estas variam de entidades bem determinadas, com explicações fisiopatológicas relativamente sofisticadas e intervenções terapêuticas coerentes com as explicações, passando por vários estágios de elaboração explicativa e de potência e coerência terapêutica, até sinônimos técnicos descritivos de sintomas, com quase ausência de explicações e com terapêuticas puramente sintomáticas, ou mesmo ausência de terapêutica.

As doenças da nosologia biomédica são muito menos freqüentes e variadas do que o universo de queixas, sofrimentos e dores relatados pelos doentes. Em grande parte das vezes, apenas uma pequena parcela do que os doentes relatam como suas doenças, dores, queixas e sofrimentos é satisfatoriamente interpretada e explicada pela nosologia biomédica. Abre-se aí um meio-de-campo que não é bem manejado pelos profissionais, cujo saber é pobre para interpretação e ação nesses casos (TESSER, 1999). Educados na ideologia científica, os profissionais tendem a dar crédito mais às verdades biomédicas de seu saber e às patologias graves e bem definidas do que aos relatos e narrativas dos doentes.

Nesse campo entram forças complexas: o dualismo cartesiano entre espírito e corpo, ou entre o físico e o psicológico, associado a um materialismo herdado da associação da doença à lesão orgânica (hoje bioquímica ou genética, mas de todo modo material) reinantes no imaginário dos profissionais de saúde, apresenta uma hierarquia. O mais importante, aí, seriam as doenças e os 
problemas físicos (cf. BALINT, 1988). De modo que o "resto" dos adoecimentos narrados, apesar do discurso ético, na prática acabam sendo relegados a um segundo plano, e muitas vezes simplesmente ignorados ou mesmo abortados (CAMARGO JUNIOR, 2003).

É comum na corporação médica (nos profissionais) uma adesão a um positivismo ingênuo e grosseiro, muitas vezes desastroso, que leva à desconsideração de tudo o que não pode ser apreendido pelo saber científico biomédico. Com isso, fica resolvida a questão dos sintomas não-enquadráveis ou parcialmente enquadráveis (lembre-se que este conjunto é talvez a maioria dos sintomas dos doentes): os não-enquadráveis "não têm nada", desqualificando o adoecimento vivido e desconsiderando-o. Os parcialmente enquadráveis têm as doenças conhecidas e o restante não importa, ainda que seja parte relevante do adoecimento para o doente. Desnecessário comentar a avalanche de frustrações e problemas daí decorrentes, inclusive éticos.

Quando tais adoecimentos são reconhecidos como legítimos e ouvidos, restam ao médico noções como somatização, fundo psicológico, psicossocial ou psicomático, transtornos funcionais etc., de pouca operacionalidade e eficácia terapêutica (pensando-se nos recursos mais comuns e valorizados dessa medicina, os quimioterápicos). Como outra possibilidade, aparece o encaminhamento ao setor especializado "psi”, o outro lado da dicotomia psique-soma institucionalizada nessa medicina, para dar conta do que não é "físico" ou "orgânico".

Nesses casos em que o imperativo ético (missão da cura da pessoa) se faz valer, ele interfere no processo de consideração das verdades e isto ainda é muito comum, felizmente. Mas os profissionais acabam por envolver-se numa outra situação difícil e comum, envolvida na medicalização social intensa da atualidade: reconhecendo a legitimidade de "adoecimentos" pouco enquadráveis e sofrimentos vários, resta comumente ao médico o uso de sintomáticos químicos largamente disponíveis no mercado, cuja eficácia é real e via de regra momentânea, tão procurada quanto muitas vezes frustrante, além de substancialmente iatrogênica (vide antiinflamatórios não-hormonais e sua relação com doenças gástricas e renais). Outros recursos ou terapias são pouco conhecidos, extremamente subvalorizados e subutilizados.

Quando o adoecimento é possível de ser diagnosticado - enquadrado pela nosologia biomédica, a efetivação de sua cura ou controle está vinculada aos critérios diagnósticos e é esperada em conformidade com o estabelecimento da terapêutica padronizada respectiva. Importa notar que a cura aí é avaliada 
pelos critérios técnicos biomédicos, a serem manipulados pelo profissional, em que a versão do doente sobre a mesma pode entrar como uma dos quesitos, ser fundamental ou ser simplesmente desnecessária. Se a doença pode ser objetivamente avaliada, a versão do doente aparece, certas vezes, como um estorvo. Assim, a doença pode estar curada, cientificamente falando, enquanto o doente não, e vice-versa.

Isso pode parecer um filigrana sem importância, relativo a doentes raros ou excepcionais, mas não é o caso. Com a recente ampliação da objetivação e manipulação dos riscos como se fossem entidades concretas, similarmente às doenças, tal situação vem ficando cada vez mais relevante, já que importantes causas de mortalidade e morbidade são "doenças" biomédicas crônicas com poucos sintomas ou por vezes nenhum sintoma, como são o diabetes, a hipertensão arterial, a obesidade.

Por fim, existem ainda as dificuldades nos casos muito frequientes em que a doença é incurável ou sem terapêutica científica, segundo o saber biomédico, quando então um "desengano" do doente ocorre via de regra. Não há muita possibilidade de relativização das más notícias ou um senso de limite e humildade no saber científico, já que não se supõe haver fora da biomedicina saber/prática veraz e eficaz ao qual o doente possa ser encaminhado. Geralmente não se dá alta por incompetência dessa medicina nem se encaminha a uma outra - a não ser muito recentemente, e de forma extremamente incipiente e rara, em alguns casos, com o crescimento do respeito às chamadas Medicinas Alternativas e Complementares.

Essas dificuldades cognitivas e operacionais de interpretação deságuam em dificuldades éticas e terapêuticas relevantes na questão do primeiro tipo de verdades aqui tratado - o da efetivação da cura vivida.

O segundo tipo de verdades - vínculo da terapêutica com a cura -, na biomedicina, será revelado pelos grandes estudos estatísticos padronizados, longínquos da experiência clínica, realizados no mundo da pesquisa científica, modelado e restrito pelos padrões-ouro metodológicos vigentes e as definições operacionais das doenças. Nessa lógica, toda distância entre a evolução vivida do doente ("sua" doença) e a evolução clínica dos parâmetros científicos de doença passa a ser inexplicável, não-objetiva, "inapreensível”. E todo sucesso não previsto deverá se repetir de tal forma que possa ser transformado em ensaio clínico suficientemente famoso e repetido para gerar saber científico e retornar ao mundo do cotidiano como verdade. Se o curador quiser produzir 
saber, terá que transformar-se num cientista, entrar numa instituição, de preferência das grandes, conseguir equipe, infra-estrutura e financiamento. E publicar em local respeitado pela corporação médica.

Outro problema envolvido nesse segundo tipo de verdades está relacionado à suposta especificidade da terapêutica: voltada para a doença específica, a ação geral do tratamento sobre o organismo como um todo e sobre a vida do doente saiu do horizonte da avaliação da biomedicina. Ou melhor, manteve-se parcialmente, traduzida e mediada por categorias flexíveis que suportam uma grande dose de iatrogenia: os efeitos adversos ou colaterais, de maior ou menor toxicidade, mais ou menos percebidos pelos doentes. Além disso, a estrutura teórica e a etiopatogenia conhecida das doenças específicas filtram a possibilidade de percepção de danos a longo, médio ou curto prazos que tratamentos biomédicos possam produzir no sujeito como um todo, criando uma "cegueira paradigmática" a respeito de possíveis "iatrogenias longitudinais" (TESSER, 1999). Ou seja: gerou-se a impossibilidade de se avaliar a evolução global do doente ao longo do tempo e relacionar sucessões de doenças (que teoricamente não têm a ver umas com as outras) e seus tratamentos no mesmo indivíduo, numa perspectiva de evolução do processo saúde-doença individual integrado.

Em síntese, a construção social e epistemológica institucionalizada das verdades diagnósticas (monopolizado pela biomedicina e cada vez mais pela indústria científica dos exames complementares e de imagem) e terapêuticas (monopolizada pelos ensaios clínicos controlados e pelas indústrias farmacêuticas) desdobrou-se em processo de relativa alienação ética/ epistemológica e de desresponsabilização social pela missão curadora por parte dos médicos, individualmente. Cabe ressaltar, obviamente, que há uma articulação coerente entre determinantes "externos" e a lógica "interna" da prática biomédica na sustentação desse processo (CAMARGO JUNIOR, 2003, p. 135).

\section{Algumas proposições: a ciência em função da cura "crua"}

Para o doente e, pode-se dizer, para a medicina em geral, antes de pensarmos em termos científicos, está posta a missão maior da cura "crua" e do cuidado. Nesse sentido, é defensável uma precedência do primeiro tipo de verdades "cruas" a ser buscado. A verdade de segundo tipo, sobre as específicas relações da terapêutica com a cura (uma relação causal ou de outro tipo 
qualquer), só se coloca uma vez estabelecido o primado da primeira verdade: é a cura que buscamos. Se podemos explicar por que se deu a cura, melhor.

A própria biomedicina não tem clareza quanto a esse aspecto, ou tem uma postura ambígua moderna, já que ora o assume, aprovando terapêuticas sem a correlata explicação fisiopatológica, apenas com o apoio de correlações estatísticas, revelando seu lado empírico agora enrijecido pelos modelos de validação estatísticos; ora o afasta, como o faz com o efeito placebo. No entanto, o importante dessa discussão é o primado e o apego à missão maior de curar a pessoa. É importante notar que nessa missão o aspecto da cura que se busca não é o formal, senão o vivido: é a eficácia, o funcionamento da cura que se busca, sua presença vivida e compartilhada.

Entretanto, a biomedicina, no seu saber, e progressivamente, na sua prática, parece ter tomado para si outro tipo de prioridade: na busca de cientificização da cura, trocou o doente pela doença, e trocou a ordem de precedência das verdades "cruas" ao instituir suas verdades "científicas", talvez também pelo medo da mentira ou ilusão e pela crença moderna na elucidação racional de tudo. Da busca inicial da cura "crua" do doente, optou pela busca da cura comprovada, comparada, "objetiva", metodologizada da doença por uma terapêutica estandardizada. Em resumo, trocou a cura desregulada, diversificada e não-controlada de muitos doentes pela ambição de cura padronizada e controlada de muitas doenças, ou seu controle. Mais ainda: apostou que o caminho para a primeira opção só poderia ser a segunda.

Não se trata de propor o abandono desse caminho. Sendo ele limitado e parcial, pode-se pensar em transformá-lo, melhorá-lo. Em três sentidos principais: primeiro, num aspecto quase psicoterapêutico. Atenuar as ilusões de controle, objetividade e submissão dos pacientes e das doenças que a biomedicina vive. Com isso, flexibilizar seu modo de controle, no sentido de que o saber terapêutico não descole dos indivíduos doentes nem pressuponha sua submissão.

Segundo, ajudar a (re)criar um saber que tranqüilize o terapeuta, possibilite maior liberdade teórico-metodológica e maior aproximação para com o universo vivido do doente, para facilitar o resgate, a centralidade do primeiro tipo de verdade como objetivo: a verdade da presença da cura vivida (ou do aumento de liberdade).

Terceiro, contribuir para o diagnóstico e a recuperação do processo em curso de alienação ética, epistemológica e social da missão de cura dos curadores 
biomédicos. Através disso, por conseqüência, uma reconstrução da competência ética e epistemológica poderia ser iniciada, a enriquecer as possibilidades práticas de aplicação e testes de interpretações e terapêuticas diversas (teste tanto cientificizado como cotidiano, empírico), bem como resgatar a relevância da individualização e contextualização dos diagnósticos e terapêuticas, da antiga "arte" da medicina, hoje cada vez mais soterrada sob o peso das verdades da biociência. Investir na construção da "competência ética" (cf. VARELA, 1996) e epistemológica dos curadores biomédicos.

Dito de outro modo, trata-se de atenuar a obsessão pela cura cientificizada da doença, sem deixar de buscar objetivá-la, porém ligando-a à situação existencial e evolução global do doente. E colocar em primeiro plano, reaprender e reensinar a missão de cura dos adoecimentos "crus" das pessoas. A primeira cura ("crua"), espera-se, deve acompanhar a segunda (cientificizada), mas isso nem sempre acontece. Pode ser subproduto da segunda, assim como vice-versa. Pode nada ter a ver com a segunda. Se são muito diferentes, então que se busque a cura das duas, juntas e ou separadas. $\mathrm{O}$ "x" da questão é que a doença "crua" e o paciente devem ter precedência, em geral. Exceções devem ser tratadas como exceções, mesmo que relativamente freqüentes; ao menos no momento atual, como objetivo tático e estratégico frente ao panorama vigente. A verdade vivida do doente deve ter precedência, mesmo que isso custe muito.

$\mathrm{O}$ argumento que autoriza a arriscar é aquele segundo o qual o custo da verdade científica também é grande. O risco é semelhante: a diferença está na sensação de proteção institucional, epistemológica e psicológica, que embota a percepção dele. Essa proteção é real, mas tem um preço: o coeficiente de "eficácia curadora" do profissional geralmente é inversamente proporcional à mentalidade protocolar de se ater às normas técnicas institucionais (científicas), porque estas, se supostamente protegem de erros, tendem a consumir e monopolizar a atenção do profissional, prendem essa atenção na grade nosológica biomédica e induzem seu afastamento do adoecimento "cru" (como trazido e vivido pelo doente), diminuindo a acurácia, embotando a percepção, a sensibilidade, a intuição e o raciocínio clínico. Doutra parte, o costume, o conhecimento e a prática prévios da administração dos riscos e efeitos adversos conhecidos das técnicas biomédicas fazem-nos parecer menores e menos perigosos; bem como seu manejo, já regrado, exime o curador da assunção de riscos e construção de cumplicidade e coresponsabilidade com os doentes nesse sentido. 
O mito do controle, da elucidação e objetivação de tudo, a mentalidade protocolar, a crença cega na ciência, o transporte automático e descuidado de suas verdades para as situações clínicas, além de outras forças, empobrecem a parceria envolvida na relação de cura e dificultam o exercício de um "curandeirismo" biomédico harmônico. É uma herança moderna, epistemológica, política e cultural herdada da filiação da biomedicina à ciência e suas lutas atávicas pelo poder (de ser a única produtora das verdades), que cabe reconhecer, administrar e transformar, como estratégia para melhorar tal "curandeirismo".

Associar o poder e a proteção institucional-político-psicológica oferecida pela ciência e pela corporação médica à aventura de ser curador pode ser defendido por princípio ético e pelo usufruto prático dos resultados obtidos por quem fez esta opção (mais ou menos intencionalmente). Trata-se de uma opção pelo ofício de curador de qualquer cultura, na biomedicina parcialmente substituída pelos rituais de iniciação na cultura científica e na corporação médica. Antes de falar de cura, a biociência fala em verdades. Desvia para si toda a capacidade desse discurso, busca monopolizá-lo. Uma vez conquistado o suposto monopólio, deve mantê-lo e ampliá-lo. Só depois fala da cura, e nos seus próprios termos. Essa é a seqüência iniciática e pedagógica de qualquer curso profissionalizante de vertente científica, particularmente o curso médico.

A pré-proposta aqui apenas mencionada é dupla: multiplicar as verdades, por um lado, relativizando-as, complexificando-as e tornando mais difícil sua determinação final. Por outro lado, subordiná-las ao princípio ético da cura do adoecimento "cru" (não interpretado cientificamente), missão primeira de qualquer curador.

Pode-se considerar, a partir desta discussão, que há um descolamento epistemológico e filosófico (da ordem dos valores) entre os objetivos da ação em saúde e os saberes científicos legitimados para informar essa ação, assim como sua construção. Esse espaço pouco visível, esse não-lugar, merece mais atenção do que simplesmente acreditar ou não na progressiva descoberta da verdade pela biociência, que permitirá o controle e cura dos adoecimentos vividos.

Talvez não seja absurdo considerar que seria melhor atenuar a obsessão pelo controle, seja da doença, seja do doente, seja da ação do terapeuta. Falase cada vez mais de controle das doenças. Supõe-se que o controle das doenças implicaria um aumento de liberdade, um maior coeficiente de cura. Poder-se-ia pensar se o controle da doença não induz ou permite o controle da pessoa e, assim, uma diminuição de sua liberdade (que seria, talvez, compensada pela 
suposta diminuição dos riscos). Merece menção, aqui, uma interpretação do adoecimento que o vê não como o fator limitante da liberdade, mas como a tentativa precária (desequilibrada) de reorganização e ou adaptação da vida, ou como sinal de alarme da necessidade dessa reorganização. Nesse sentido, a busca do controle da doença poderia significar a busca da permanência de um modo de viver em crise, que exige e necessita alguma mudança, e auxílio para essa mudança.

Não se trata de acabar com ele, apenas que a obsessão pelo controle é contraprodutiva: seu excesso gera mentalidade burocrática, agressividade política, alienação epistemológica e desresponsabilização ética. Além disso, atrofia outras formas de orientação, aprendizado, vivência e percepção menos rígidas, mais criativas, mais solidárias, mais humildes. Pode-se pensar, ainda, que para tratar da vida em crise ou doente (a vida, a coisa mais incontrolável, que sempre resiste, escapa e surpreende), o controle não deveria ser um valor tão rigidamente adotado e operado. Se a vida, a saúde e o adoecimento são complexos, a intervenção e a pesquisa sobre eles poderiam se pautar por saberes e métodos mais complexos e menos controlados, talvez com melhores ou equivalentes resultados.

Eis uma característica do enfoque aqui pretendido: notar que a ciência não acaba, não se prejudica necessariamente renunciando ao monopólio da ação sobre a cura, a saúde, a doença (ou, mais propriamente, à ilusão de ter o monopólio dessa ação). Ela pode se enriquecer quando é usada para a cura. E também quando associada ao que não é ela para a cura. E pode não perder nada, aliás, até crescer, quando é evitada em prol da cura e ou da liberdade do doente.

A renúncia ao controle da natureza ou a renúncia a essa ilusão de controle, deve-se reconhecer, é pedir demais à biociência e aos biomédicos. Isso faz parte da sua história e da sua tradição, por isso é fonte inesgotável de problemas para ela e para os doentes. Há que amenizar esse pedido. Trata-se tão somente, e eminentemente, de flexibilizar o que se enrijeceu obsessivamente - misturado com atávicas lutas políticas e ambições de poder e controle -, resgatando a tendência saudável, cética e ética ali envolvida, com mais flexibilidade. Mas, sobretudo, de resgatar e fomentar a responsabilidade ética e epistemológica dos curadores oficiais, os médicos. 


\section{Referências}

ALMEIDA FILHO, Naomar. A clínica e a epidemiologia. Salvador: APCE, 1992.

ALMEIDA, E. L. V. As razões da terapêutica: racionalismo e empirismo na medicina. Niterói: EdUFF, 2002.

BALINT, Michel. O médico, seu paciente e a doença. Rio de Janeiro: Atheneu, 1988.

BRONOWSKI, Jacob. O senso comum da ciência. Belo Horizonte: Itatiaia, 1977.

CAMARGO JUNIOR, K. R. Biomedicina, ciência \& saber: uma abordagem crítica. São Paulo: Hucitec, 2003.

CAMPOS, Gastão Wagner de Souza. Reforma da reforma: repensando a saúde. São Paulo: Hucitec, 1992.

CANGUILHEM, G. O normal e o patológico. Rio de Janeiro: ForenseUniversitária, 1978.

CLAVREUL, Jean. A ordem médica: poder e impotência do discurso médico. São Paulo: Brasiliense, 1983.

CZERESNIA, D.; FREITAS, C. M. (Org.) Promoção da saúde: conceitos, reflexões, tendências. Rio de Janeiro: Fiocruz, 2003.

DALMASO, A. S. W. Estruturação e transformação da prática médica: técnica e ciência na segunda metade do século XX. 1998. Tese (Doutorado em Medicina Preventiva) - Departamento de Medicina Preventiva e Social, Faculdade de Medicina, Universidade de São Paulo, 1998.

FEYERABEND, P. K. Adeus à razão. Lisboa: Edições 70, 1991.

. Contra o método. Rio de Janeiro: F. Alves, 1985.

FLECK, L. La génesis y el desarrollo de un hecho científico. Madrid: Alianza Editorial, 1986.

GAYON, J. Epistemologia da medicina: epistemologia da medicina, epistemologia da biologia, apenas epistemologia. In: RUSSO, M.; CAPONI, S. (Org.). Estudos de filosofia e história das ciências biomédicas. São Paulo: Discurso Editorial, 2006. p. 38-87. 
GONÇALVES, R. B. M. Reflexão sobre a articulação entre investigação epidemiológica e a prática médica a propósito das doenças crônicodegenerativas. In COSTA, D. C. (Org.): Epidemiologia: teoria e objeto. São Paulo: Hucitec, 1994. p. 39-86.

ILLICH, I. A expropriação da saúde: nêmesis da medicina. São Paulo: Nova Fronteira, 1981.

KUHN, Thomas. S. A tensão essencial. Lisboa: Edições 70, 1989.

. La estructura de las revoluciones científicas. México: Fondo de Cultura Económica, 1986.

LACEY, Hugh. Valores e atividade científica. São Paulo: Discurso Editorial, 1998. (Coleção Filosofia da ciência \& epistemologia).

LATOUR, B. A esperança de Pandora: ensaios sobre a realidade dos estudos científicos. Bauru, SP: EDUSC, 2001.

. Ciência em ação: como seguir cientistas e engenheiros sociedade afora. São Paulo: UNESP, 2000.

Reflexão sobre o culto moderno dos deuses fe(i)tiches. Bauru: EDUSC, 2002.

LATOUR, Bruno; WOLLGAR, Steve. A vida de laboratório: a produção dos fatos científicos. Rio de Janeiro: Relume-Dumará, 1997.

LUZ, Madel. T. Racionalidades médicas e terapêuticas alternativas. Rio de Janeiro: Instituto de Medicina Social, Universidade do Estado do Rio de Janeiro, 1996. (Série Estudos em saúde coletiva, 62).

NOGUEIRA, R. P. A saúde pelo avesso. Natal: Seminare Editora, 2003.

RORTY, R. Objetivismo, relativismo e verdade: escritos filosóficos I. Rio de Janeiro: Relume-Dumará, 2002.

SAYD, J. D. Mediar, medicar, remediar: aspectos da terapêutica na medicina ocidental. Rio de Janeiro: EdUERJ, 1998.

TESSER, C. D. Epistemologia contemporânea e saúde: a luta pela verdade e as práticas terapêutcas. 2004. Tese (Doutorado em Saúde Coletiva) Universidade Estadual de Campinas, Faculdade de Ciências Médicas, Universidade Estadual de Campinas, 2004. Disponível em: <http:// libdigi.unicamp.br/document/?code=vtls000317960 > . Acesso em: 23 jan. 2007. 
. Medicalização social (I): o excessivo sucesso do epistemicídio moderno na saúde. Interface - Comunic, Saúde, Educ, Botucatu, SP, v. 10, n. 19, p. 61-76, jan./jun. 2006.

. Medicalização social (II): limites biomédicos e propostas para a clínica na atenção básica. Interface - Comunic., Saúde, Educ., Botucatu, SP, v.10, n. 20, p. 347-62, jul./dez. 2006.

- A biomedicina e a crise da atenção à saúde: um ensaio sobre a desmedicalização. 1999. (Dissertação) - Mestrado em Saúde Coletiva, Universidade Estadual de Campinas, Faculdade de Ciências Médicas, Universidade Estadual de Campinas, 1999. 219 p. Disponível em: <http:// libdigi.unicamp.br/document/?code=vtls000199171 > . Acesso em: 23 jan. 2007 VARELA, F. Sobre a competência ética. Lisboa: Edições 70, 1996.

\section{NOTA}

- Médico, sanitarista, doutor em Saúde Coletiva, professor adjunto no Departamento de Saúde Pública, Centro de Ciências da Saúde, Universidade Estadual de Santa Catarina. Endereço eletrônico: charlestesser@ccs.ufsc.br. 
Truth in biomedicine, adverse reactions and side effects: an introductory reflection

This article presents a reflection on the construction and application of scientific truths, within clinical activity, and its relationships with physicians' ethical mission. It analyzes troublesome aspects of the transformations made by biomedicine in two critical moments of truth production: 1) the accomplishment of cure; and 2) its relationship with therapeutics. The ethical mission of biomedicine is to cure patients and to promote their health, but its knowledge is focused on cure or control of specific diseases. The truths made by science supply the tendency for the conversion of patients into diseases, and their cure into cure or disease control and its risks. This involves an ethical and epistemological process of "deresponsibilization" of biomedical healers. The ethical "deresponsibilization" changes practitioners' identity, who begin to regard themselves more as scientists and less as healers. The epistemological "deresponsibilization" is the projection of all competence for production of true knowledge in biomedical science. This fact exempts practitioners from producing knowledge for their own activity, disqualifying all knowledge of patients and other non-scientific healers. This article proposes a critical, flexible and pragmatic perspective in the relationship with scientific truths, and the submission of this relationship to the practitioners' role of healers, centered in the patients and in their cure, conceived as more autonomy and more freedom. It points out to the need of rebuilding the ethical-epistemological responsibility of practitioners.

Key words: Medicine - practice; Philosophy; methodology; public health; medical ethics. 